\title{
ENSURING BUILDING PERFORMANCE THROUGH SIMULATION
}

\author{
Dana K. Smith \\ National Institute of Building Sciences \\ 1090 Vermont Avenue, NW, Suite 700 \\ Washington, DC 20005 USA
}

\begin{abstract}
This presentation highlights multi-faceted decision-making concepts for facility design and construction and identifies opportunities for the use of a building information model (BIM) for simulating the facility lifecycle, from design, through construction and after handoff to the owner and occupant. Whether it is the architect, engineer or other team member on the project, having the authoritative source provide design and functional information into a BIM allows the facility owner to better understand how the facility will function prior to construction and ensure optimum functionality after occupancy. With a BIM, owners will be able to understand the cost of design decisions on operations on an annual basis for the life of the facility. A BIM life-cycle-based simulation of facilities provides the predictive information necessary to profoundly improve the way a facility is built and operated because everyone involved in the process can work according to a plan defined prior to construction.
\end{abstract}

\section{INTRODUCTION}

Facilities consume $71.8 \%$ of the electricity and over $40 \%$ of all energy consumed in the United States. They also produce $39.6 \%$ (DOE 2007) of the emissions that contribute to global warming and pollute the atmosphere. In addition, the most staggering fact is that facilities consume $75 \%$ of the earth's raw materials (Matos 1998). This number covers facilities and infrastructure, including buildings, roads, dams, bridges, and similar construction. The number drops to $40 \%$ if looking at buildings alone (Matos 1998). The construction industry is beginning to own up to these facts because of efforts such as those of United States Green Building Council's (USGBC) Leadership in Engineering and Efficient Design (LEED) and various other "green building" related organizations in spreading the word. However, a truly optimized and holistic approach to solving the energy and sustainability problem has not been implemented quite yet. There is still a significant disconnect between the design and construction sector and the operations and sustainment sector in the construction industry. Each of them is moving forward at relative breakneck speed independently with little knowledge or awareness of the others' successes or expanded capabilities.

The facilities industry is significantly fragmented in the way it does business. Each stakeholder in the business process completes his or her own tasks and does not tend to share information freely. This is heightened by the fact that each software application solves problems for a single stakeholder, and each requires its own information to be loaded for the specific application. In addition, software programs are mostly stand-alone and information does not typically pass between software programs. This desired open and free information flow is referred to as interoperability; when stakeholders work together it is called collaboration and, sadly, there is little of either in place today. However, solving the problems related to these current disconnects is simply not an option. Lack of interoperability is hampering the industry's ability to solve problems holistically which is having a catastrophic outcome when it comes to dealing with environmental and energy related issues. Solving the interoperability problem is a role of the buildingSMART alliance. Some vendors are attempting to purchase companies and create proprietary interfaces to resolve the problem, but this ultimately serves to limit the options users have to select the software of their choice with specific capabilities related to specific problems being solved. One approach that provides software tools to help make decisions that support a truly sustainable future for the planet is an open standards approach which will allow all tools to be interoperable. Technology solutions are only part of the problem, there are also significant cultural 
problems that must be overcome. Many things can be done today to help minimize or lessen the current out-of-control energy and environmental problems, but many are not yet in vogue or are not being taken advantage of and some have yet to be invented. While some companies are developing zero waste factories $\langle$ http://www. zerowaste. org/ $>$ and others are re-cycling at significantly higher rates than before, there is still not an equal understanding of sustainability issues across the country. Because the whole planet is affected, the problem needs to be looked at equally or holistically, not in just one area. Many of the problems are perpetuated by the lack of a strong information base on which to found informed multi-faceted decisions.

Many issues must be dealt with concurrently, instead of optimizing just one aspect at a time. In many cases, the current approach leads to situations where one solution ends up negatively affecting another facet. However, individuals on the project team may not be aware of the negative impact, because it is not in their "area of expertise". Therefore, a collaborative decision must be arrived at with all the experts involved. However they may be able to be involved electronically. Through information-based simulation a lot can be done to improve, if not provide a total solution to many of the current technical problems related to the impact of facilities on the ecostructure.

The buildingSMART alliance <www.buildingsmartalliance.org> is focused on coordinating many of the individually important and complex aspects involved in problem solving that have traditionally been looked at as nearly independent point solutions because of the lack of information interoperability. It has only been in recent years that the potential for multi-faceted analysis could take into account many aspects of a problem. Historically this has been perpetuated by specialized decision makers and product marketing techniques that use independent software tools to optimize a solution for their specific aspect of the problem. For example, the designer of the exterior skin of the building needs to take into account a myriad of aspects to include spatial orientation, daylighting potential, acoustic attenuation, energy usage, LEED rating, ufactor, dew point, use of green roofs, rain water capture, both solar collection for heat and electricity, moisture permeability, resistance to mold and rot, structural integrity, ability to withstand wind pressure, seismic event impact, raw material usage and availability, combustion, flame spread, out gassing, material safety, carbon footprint, glazing type, fabrication method, applicability to pre-construction, material availability, delivery schedule, skill of the labor pool to install, initial cost, life cycle cost, durability, preventative maintenance, warranty length, product life, ability to re-cycle at end of life, impact on the productivity of the people or process occupying the space and of course aesthetics. That is just the beginning, as similar decisions need to be made throughout the facility. Based on the complexity many of the decisions historically have caused unexpected results leading in system failures of one type or another.

The buildingSMART alliance and the Open Geospatial Consortium recently demonstrated how manipulation of the exterior skin of the building affects energy usage and the quantities of materials used. The joint project was funded by many notable and interested parties <http://www. opengeospatial.org/projects/initiatives/aecoo-1>. While this project was significant in itself, it also demonstrated the potential interoperability of information on a much broader scale in that the information did not have to be re-entered into each tool independently. Instead the same information was shared using the open Industry Foundation Class (IFC) standards. This is only the beginning of interoperable information sharing. Information sharing allows more analysis to take place since one of the significant costs of analysis is data entry.

Another major factor is the lack of capability of current analysis tools. If an environment is created where the same data can be repurposed then not only is multifaceted analysis possible, but there is more certainty of the results since everyone is using the same information and definitions for such items as length, height, width, weight and a myriad of other such measures are common. Another buildingSMART alliance project, entitled "Specifier Property Sets" or SPie, is being developed to ultimately coordinate the inclusion of manufacturer products into building information models.

In the current environment of design and construction, the likelihood of the information that the engineer enters into a single-point analysis tool such as glazing type, being the same as that which is specified and ultimately purchased is not very high. This is due to the many disconnects, sequential nature and time constraints of how business is currently done and information is shared. The only way to improve this situation is to become profoundly more productive with the time available. Owners already are very frustrated. They feel it takes too long and costs to much to produce a facility and they are not willing to pay more or wait longer for the facility. Therefore, it is necessary to expand everyone's thinking to look at a longer period, not in delivery, but in operations--a life cycle view--to understand not only how to build a more energy and material efficient building but to assess and predict its function throughout its life. The goal is to ensure that people are able to understand the entire facility experience long before it is a physical reality.

When most people approve the construction of their facility, they have little understanding of how the facility will work for them. It is estimated that $90 \%$ of people cannot read a set of drawings (Smith 2009). Therefore, they are typically approving something based on previous life experiences, not based on any experience with the new spaces and relationships being created. This leads immediately to changes in the facility from day one because some aspect of the facility did not meet expectations or function in the way it was anticipated by the occupant. Unfortunately, in some cases, the changes can be accommodated, in others one simply has to live with the results. In many cases, those results will affect the productivity of the 
people or process that occupies the facility. Quite a few years ago the Advanced Building Systems Integration Consortium (ABSIC) at Carnegie Mellon University identified that improving the productivity of the people or process that occupy a facility by just $3.8 \%$ would pay for the entire facility - design, construction and operations and maintenance. It would therefore make sense to simulate productivity in the facility prior to construction so that even minor distractions from optimum performance could be eliminated. This is buildingSMART.

Another example of this concept is designing and constructing facilities to code in earthquake regions. Code requires that the facility not fall down so that people can exit the facility safely. Unfortunately, it does not guarantee that the facility will be usable after an event. If a facility is not usable then people are displaced from their living quarters and companies are not able to carry on business. Since the costs associated with the people or processes that occupy facilities far exceed the cost of designing, building or operating the facility, it only makes sense to take measures to ensure that the impact of the discontinued use of a facility is minimized. Yes, insurance can be purchased beforehand to address continuation of business operations for a company and to offset costs of various perils that can befall a home, but if one could ensure that the impact of the peril was minimized or eliminated, then the cost of premiums could be significantly reduced and more importantly disruption of the business would not occur. Another significant factor often overlooked is that any unusable facilities must be razed and will end up expanding landfills. Even in good times, facilities contribute up to $40 \%$ of landfills (USGBC 2008) if multiple facilities are destroyed then this problem increases substantially. The same logic discussed above is true of fire, flood, and wind damage. Insurance companies set rates based on risk. We have already seen where discounts are provided for air bags in cars, or alarms and sprinklers in buildings. It is also expected that one will pay more if they live in a flood zone. Taking undue risk and then covering our loss with insurance, is not a sustainable practice but is practiced because some desirable locations are in high risk areas. However, when in a high-risk area, building a sustainable building is still far better than one that is not and building information modeling can help simulate certain levels of disasters to evaluate how facilities will react. Insurance rates can then be set based on the "sustainability factor".

\section{ENTER BUILDING INFORMATION MODELING}

Many of the problems discussed could be minimized with proper analysis during the design phase of a project. Design can be significantly enhanced using simulation so that decisions can be evaluated in totality with the rest of the project. Much work still needs to be accomplished to realize this new environment. Construction is already the first implementer of simulation in this market as they are using construction scheduling to optimize deliveries, and perfect sequencing to include preconstruction of modules of the facility. These modules are delivered "just in time" and simply assembled on site. However, contractors often have to create their own models as the design community is not yet providing adequate or usable building information models even when they are created during the design phase of a project.

As defined in the United States National BIM Standard Version 1, Part 1, released January 2008 <http://www.buildingsmartalliance.org/nbims/> a building information model (BIM) is a digital representation of physical and functional characteristics of a facility. As such, it serves as a shared knowledge resource for information about a facility forming a reliable basis for decisions during its life cycle from inception onward.

From the definition, one can see that the discussion to this point related to supporting simulation fits well within the bounds of a BIM. The desire to understand how a facility will function throughout its life and evaluating that functionality during the design phase points to simulation as an excellent choice.

One of the benefits of a BIM is the ability to involve all facets of the design and construction team early in the process and produce a nearly true as-built model prior to physical construction. On average, if one identifies all the stakeholders involved in the decision making process as in the earlier example about exterior closure, it is approaching three dozen people, many specializing in only one aspect of the solution. To bring that group together on each consultation is certainly impractical, even in today's web-conference-based society. Therefore, their experience needs to be captured in a rules-based analysis tool that can represent their interests. While no tool is going to simulate all experiences, the 80-20 rule will likely come into play which states that $80 \%$ of issues can be easily standardized and that $20 \%$ will be unique, the corollary to this is that it takes $80 \%$ of the effort to get the last $20 \%$ of a problem solved. Therefore the team should certainly focus its aim to resolve the majority of the issues first and then solve the unique situations at a later date.

The facilities industry has been involved in simulation of various types of facilities or portions thereof for well over twenty years. It is now just to the point where it can simulate in a near real life timeframe with the accompanying graphics to provide a near real life condition. The computer gaming industry has provided the industry with many of the tools, yet the majority of design practitioners are still not taking advantage of all the opportunities. While most people in the industry are using scheduling extensively during construction, the ability also exists to involve time phasing during the operational life of a project to see how the replacement cycles will affect future budgets of multiple facilities in a campus or military installation 
environment $<$ http:// onuma.com/services/FederalFacilitiesCouncil.php $>$. This potentially enables all stakeholders to participate and gain insight into how the facility will function over time. In simulation, while one cannot yet feel hot or cold, sense a draft or hear ambient or specific equipment noise in facility simulations, they will eventually incorporate some of the other senses to create as real an experience as possible. How many times has a room filled with people or added equipment in the summer only to find out that the air conditioning system was not able to keep up? With simulation one can predict the impact of many bodies or equipment in a space over a period of time. Of course, the problem is worse in the summer than it is in the winter, this too can be simulated. Alternatively, one may be able to determine that a certain location in a room may be deemed unusable for people sitting and working due to a draft and could reduce productivity. However this may not be a problem in other instances, in fact the increased air flow may be desired. Equipment noise may also make an area unusable for a particular function, such as a conference room. Predicting those situations beforehand through simulation would make for a much happier client. Currently, one must settle for the visual experience backed up with mathematical information. Clearly the technology is moving in the right direction, however it has not yet reached the desired state.

In many of these situations, inherent awareness of the risks already exist, because critical facilities such as hospitals and nuclear reactors are designed to withstand significantly more catastrophic events, and certain critical facilities have more scrutiny that others. However, evidently the life cycle math has not been done to figure out the overall societal benefits of improving a facility's sustainability, usability and functionality across the board or surely more facilities would incorporate simulation and building information modeling.

Social and political aspects of people's lives often cloud their best intentions and slow down real progress. This is true in the BIM world also. Human relations and cultural affects are at the heart of what is slowing down many of the implementation efforts. While certainly not the topic of this paper, this is being mentioned so that the reader is reminded that those are often even more complex issues than the seemingly complex ones attempting to be solved through technology.

While the risks of pollution and raw material depilation have not been well understood some now suspect that the reckless abandon that has been enjoyed in the past may have catastrophic long-term results. Some are sounding the alarm, while others are still not sure, again human nature and politics is clouding judgment and there is a need to elevate these decisions to a true science and not simply conjecture. Simulation may have even a more significant role in helping people work together to allow the outcome of current decisions to be seen over a longer period of time.

Because of BIM's relative newness, there are very few metrics related to the benefits of modeling facilities, therefore much of this too is seemingly conjecture. Because of that, there is little impetus from owners or the general population to request BIM or simulation of a facility except in specific high risk situations . Many owners are frustrated at the seemingly inept process of acquiring a new facility, yet are not adapting a more holistic view oriented toward the facility life cycle where many of the issues may be uncovered and appreciated. It appears that it may be more acceptable to be surprised when problems occur than to plan ahead and attempt to eliminate them.

Each discipline in the life cycle tends to solve problems primarily optimizing their aspect of the facility and not necessarily the facility as a whole over the entire lifecycle. Because of this, life cycle costs are now rarely part of the decision process. The entire facilities community is programmed to make decisions based on initial cost. This is reinforced by the way taxes are assessed, and business processes are split, primarily because it is easier and "it is the way we have always done it". However, every manufacturer of a product can identify the mean time to failure of their product to optimize design and determine warranty periods. That is engineered into each product. One can purchase products from many vendors that are classified as good, better or best. If one builds a facility that only needs to last until it is sold, one's mindset should be different than if onewill be responsible for it for 100+ years. Unfortunately, the objects currently available in modeling do not contain any of the information needed to make good life cycle or holistic decisions. Most currently only provide geometry and possibly initial cost. Therefore, practitioners cannot truly understand what the overall impact is of a decision based on such sketchy information. The buildingSMART alliance is beginning to work on standards, which will identify the information required to make decisions that are more informed.

In the case of the structural example used earlier as it relates to an earthquake, what is the value of adding additional bracing so that the facility is usable after an event? In Japan, this approach is much more often implemented, likely because they have had more experience with catastrophic seismic events. A recent facility built at the University of Southern California, the College of Cinematic Arts, was designed to be sustainable for over 100 years in an earthquake zone. This involved all aspects of the facility lifecycle. Sustainability not only needs to be designed into the facility, but also needs to be sustained and understood by physical plant personnel. They too are candidates involved in implementing simulation techniques.

The computer gaming industry has introduced many people to some of the facility related simulation possibilities in a sometimes rather violent way, but there are also more tame simulation games that begin to allow people to see the results of their business decisions. These should be at the heart of the BIM simulation effort, but they are not yet in the mainstream professional practice. While possibly not as exciting and spell bounding, they will help in dealing with real issues related to sustainability. 
In hospital design, simulation is more routinely used to see how spaces such as emergency rooms or operating rooms will function during certain procedures; even stressing them to specific crisis situations never actually expected to occur. This is not unlike the training that pilots go through in aircraft simulators where all types of situations are thrown at them to see how they will react. Simulations can also track the path of patients and visitors to minimize cross contamination of spaces in hospitals. In other cases, courthouses have been analyzed to see how judges, courtroom personnel, prisoners, witnesses, juries and others will interact, or not interact during the course of various operating environments. In one analysis, over 2,600 routes were analyzed in a relatively short period using a rules-based system to ensure that security would not be compromised (Eastman 2008). We are also beginning to understand that waste in one function depletes capability in another. For example, school districts are looking seriously at optimizing energy usage so that the savings can be passed to improve education curriculum.

A fully developed BIM should provide all the information needed to support simulation, although the model view needs to be developed to identify the information requirements. It is an appropriate approach to collect data as the information is collected during the normal design and construction phases of a project. It is also appropriate to capture design intent and constraints in a format that can be used for later evaluation. If a facility is not performing the way it was expected, then the decisions leading to that design approach can be identified and changed if needed. In this way, true value engineering can also be practiced as it was meant to be so that it is not simply cheapening a facility as it has evolved to doing. It should be used to identify better ways to provide the same function, as it was intended.

There is still a lot of work to do to get to a point where a BIM can be loaded into a simulation tool, but the potential is there through the use of an international standards-based approach using IFC's or ISO/PAS 16739 <http://www.iso.org/iso/catalogue_detail.htm?csnumber=38056>. This coupled with half a dozen other related ISO standards supporting IFC's can be the path to achieving an environment where simulation can be implemented directly from a BIM and easily used on nearly every project. If the industry can get to this point then interactive simulation linked to the design tool would be possible, making it much easier to add an additional foot of space by pushing out a wall and instantly see what all other effects would result from that change.

In the facilities world kitchen design, has long been done in 3D. This has allowed the customer to simulate their experience in the space prior to finalizing the design. Once determined that the optimum design has been attained, then the model is sent directly to fabrication of the cabinets, countertop and ordering of appliances. Why this limited activity has not expanded faster in the United States is a bit puzzling. In Finland, they are now designing houses that way, fabricating them in Estonia, and delivering the final product by boat.

If simulation is properly applied during design and prior to physical construction, the owner and occupant would be able to create a reserve fund so money could be set aside at a constant rate to accommodate the expected annual costs in operations as well as maintenance, even setting aside an emergency fund should something not under warranty fail prematurely. Sensitivity analysis can also be accomplished to identify the impact of various investment strategies and economic conditions such as inflation. Essentially a very accurate proforma can be developed and then tracked over the occupancy of the facility. This approach would benefit both existing and future occupants.

\section{ROLE OF SIMULATION AFTER HANDOVER}

While the first two to three years of a facility's life are typically spent in design and construction, the real opportunity comes in the 100+-year life cycle of the facility. At handoff to the customer, if commissioning of the facility is done, then this begins the process when the owner and the team involved can check to see if the design, engineering, construction process, modeling, and simulation done prior to construction accurately predicted the outcome. If it does not, then the industry will need to do a root cause analysis and implement change to correct inaccuracies and improve in the future. Currently, problems only involve one facility, one owner, and one designer. Feedback rarely gets back to anyone in the industry much less the software vendors so they can improve their analysis tools. The industry needs a business process in place to collect centrally those anomalies, or it will be destined to repeating the same bad practices indefinitely. This is likely also a reason why it has not seen faster adoption of commissioning because the feedback loop is not in place. The findings need to go toward improvement for the industry as a whole, not just on one facility. The building information model can help in the commissioning process extensively and support a feedback process. The actual conditions under which the building is operating need to be compared to what was anticipated so that a complete and accurate model can be provided to both the designer and the facility operator for long-term use.

While commissioning is the first step, it certainly should not be the last. While in many cases, the facility may initially appear to function as designed, it is the sustained operations and maintenance that will tell the long-term story. With facilities becoming more complex to operate, it is becoming more difficult to pass on the operating instructions and the design intent to 
successive facility managers. Again, the building information model can be the knowledge base for everyone involved in the operations, sustainment, and occupancy of the facility. Not having a BIM to this point has led to massive efforts to collect and re-collect information with little understanding of the complete picture and certainly the design intent. This has lead to facilities not operating at their optimum levels. Even the tracking of warranty information has been a task that most are not doing. This can often lead to paying for replacement equipment that should have been covered under warranty. That, coupled with poor preventative maintenance, only compounds the problem because the lack of maintenance records causes some warranties not to be honored. We look to approaches such as the Construction Operations Building Information Exchange (COBIE) <http://www.wbdg.org/resources/cobie.php > to help ultimately eliminate this problem as its techniques are fully implemented.

The time for implementing this comprehensive approach is right. The cost of sensors is going down; the rise of networking at all levels, including wireless, is increasing; and the collection of information about the operation of a facility is rather inexpensive and simple, comparatively. At this point, a simple "check engine light" concept may be the first step in identifying that a problem may exist. For, just as with cars, the days of do-it-yourself maintenance have left most of us in the dust. If the facility is not functioning as it was simulated and predicted to perform, then some corrective action needs to take place, likely by a professional. Again, in most cases, this approach needs to be at a higher level than just fixing one problem on one building.

In the case of an owner of a large number of facilities such as the Department of Defense, with some 545,000 facilities worldwide <http: / / www.acq.osd.mil/ie/download/bsr/BSR2008Baseline.pdf>, this change will have a huge impact. However, university campuses, school districts, and facilities such as hospitals will also be significant beneficiaries of a better understanding of their facilities by applying BIM and simulation. While there will need to be an initial commitment, full implementation can be expanded over time to the entire portfolio of facilities. It will be more easily established when the facility is new or undergoing major renovation. However once a BIM is established, all the information collected can be stored there for future use so that it never has to be re-collected again.

The current total cost of doing business, and thus return on investment, has been difficult to quantify. While it easily will include the initial cost of the facility, the operating and maintenance cost have been more difficult to identify because of the industry fragmentation--no one has the responsibility to follow through on costs or operations. In addition, many facilities do not spend what is required on maintenance. Therefore the cost may appear much lower than it really is. It is hard to determine if a piece of equipment needed to be replaced early due to poor preventative maintenance or see what the impact of deferred maintenance truly was. A system failure that prevents full occupancy of the facility would be catastrophic from a return on investment point of view if it were even assessed. This failure to measure is largely because the cost of a facility related to the cost of occupancy productivity is so low. The focus has moved to payroll, not facility operating costs. In addition, detailed information such as the cost and time ramifications of performing service calls without having the manuals available is typically never recorded.

For example, what would the impact be of knowing what the part numbers were for a piece of equipment and that they were already in stock--especially because those are the parts that wear out quickly--before the service person arrived on site? What is the advantage of predicting the failure of a piece of equipment and replacing it on an expected schedule instead of on an emergency ticket on someone else's schedule? Many new software tools do now remind facility managers to do preventative maintenance on co-located equipment when someone is already doing a task on another piece of equipment nearby, if that data is captured. In addition, often a piece of equipment will show signs of impending failure based on poorer performance and that can be detected, if one is able to see the degradation using sensors. In this case, first, the data has to be loaded and then something or someone has to be monitoring its performance. Relatively inexpensive lifecycle tasks, if they are planned.

This is not to assume that any of this is easy to accomplish, the industry has been working on many of these problems a good many years. However this is now the information age and the construction industry has only just begun to take advantage of all the tools available. Many of these ideas will come of age as building owners replace aging infrastructure and become more aware of the costs of inaction. However, it will take time and a coordinated effort--one that can be enhanced by using BIM and simulation.

\section{REFERENCES}

Eastman, C., P. Teicholz, R. Sacks, and K. Liston. 2008. Bim Handbook: A Guide to Building Information Modeling for Owners, Managers, Designers, Engineers and Contractors

Smith, D. K. "The USC School of Cinematic Arts: The Arrival of Spring in the Facilities Industry", Journal of Building Information Modeling, Spring 2009 <http: / / www.wbdg • org/references/jbim.php> 
Smith, D. K., and M. Tardif. 2009 Building Information Modeling: A Strategic Implementation Guide for Architects, Engineers, Constructors, and Real Estate Asset Managers

Matos, G. and L. Wagner. 1998. "Consumption of Materials in the United States, 1990-1995". Annual Review of Energy and the Environment

U.S. Green Building Council. 2008. Green Building Facts

\section{AUTHOR BIOGRAPHY}

DANA K. SMITH, FAIA lectures and is a writer for the AECOO community. He is co-author of the book Building Information Modeling, A Strategic Guideline for Architects, Engineers, Builders, and Asset Managers, published by John Wiley and Sons. Deke is Executive Director of the buildingSMART alliance a council of the National Institute of Building Sciences where he is on staff. $\mathrm{He}$ is also active in buildingSMART International and on their executive committee. $<$ ww. buildingsmartalliance.org> 